\title{
Genetic analysis of acidocin B, a novel bacteriocin produced by Lactobacillus acidophilus
}

\author{
Rob J. Leer, ${ }^{1}$ Jos M. B. M. van der Vossen, ${ }^{2}$ Mariska van Giezen, ${ }^{1}$ \\ Johannes M. van Noort ${ }^{3}$ and Peter H. Pouwels ${ }^{1}$
}

Author for correspondence: Rob J. Leer. Tel: +31 15 843171. Fax: + 3115843989.

1 TNO Nutrition and Food Research Institute, Department of Molecular Genetics and Genetechnology, PO Box 5815, 2280 HV Rijswijk, The Netherlands

2 Department of Microbiology, PO Box 360 , 3700 AJ Zeist, The Netherlands

3 TNO Prevention and Health, PO Box 2215, 2301 CE Leiden, The Netherlands

\begin{abstract}
The genes encoding the production of acidocin B, a bacteriocin produced by Lactobacillus acidophilus strain M46 which is active against Listeria monocytogenes, Clostridium sporogenes, Brochothrix thermosphacta, Lactobacillus fermentum and Lactobacillus delbrueckii subsp. bulgaricus, but inactive against most other Lactobacillus species, were previously localized on a $4 \mathrm{~kb}$ Xbal-HindIII fragment of plasmid pCV461. In the present work, DNA sequence analysis revealed the presence of three consecutive ORFs, which potentially code for hydrophobic peptides composed of 60, 91 and 114 amino acids, respectively, and a fourth ORF of opposite polarity which could potentially encode a peptide of 59 amino acids. The middle ORF (ORF-2; acdB) was identified as the gene encoding acidocin $B$ by comparing the amino acid composition of highly purified acidocin $B$ with the deduced amino acid sequence of ORF-2. Our results suggest that acidocin B is synthesized as a precursor which is processed at a site which conforms to the ' $-3,-1$ ' rules of von Heijne to yield active acidocin B (59 amino acids). The presence of an immunity-protein-encoding gene on the $4 \mathrm{~kb}$ Xbal-BamHI fragment was deduced from the capacity of a plasmid vector harbouring this fragment to confer immunity upon transformation of $L$. fermentum NCK127. One of the three non-assigned ORFs may encode this immunity protein.
\end{abstract}

Keywords: Lactobacillus acidophilus, bacteriocin, acidocin B

\section{INTRODUCTION}

Lactic acid bacteria (LAB) are traditionally used to preserve food and feed. The metabolic activities of LAB play an important role in this respect (Gilliland, 1985). The formation of copious amounts of acidic end-products, primarily lactic acid, from the fermentation of carbohydrate-rich substrates such as grain, silage, milk and vegetables is largely responsible for creating an environment unfavourable for the growth of spoilage organisms. Some strains of LAB also produce bacteriocins, proteins with bactericidal activity against closely related bacteria (Tagg et al., 1976). The majority of bacteriocins produced by LAB can be classified into four distinct groups based on biochemical and genetic characteristics: (i) small

Abbreviation: $L A B$, lactic acid bacteria.

The EMBL accession number for the sequence reported in this paper is Z34920.
( $<10 \mathrm{kDa}$ ), heat-stable membrane-active peptides, (ii) large $(>30 \mathrm{kDa})$, heat-labile proteins, (iii) lantibiotics, small $(<5 \mathrm{kDa})$ proteins containing the unusual amino acid lanthionine, and (iv) complex bacteriocins comprising other chemical moieties besides protein (Klaenhammer, 1993).

During recent years a number of peptide bacteriocins have been isolated, purified and studied biochemically and genetically. Mature, class I bacteriocins are hydrophobic peptides, some of which require the presence of a second peptide for activity (Nissen-Meyer et al., 1992). The two peptides are presumed to oligomerize and form membrane pores and ion channels (Nissen-Meyer et al., 1992). Class I bacteriocins are synthesized as precursor molecules that are cleaved after a characteristic Gly-Gly doublet, invariably present at positions -2 and -1 with respect to the mature protein. Genetic characterization of bacteriocin production has shown the presence of operon structures, comprising one or two genes encoding the 
bacteriocin, an immunity-protein-encoding gene, and genes implicated in secretion and maturation of the bacteriocin (Belkum et al., 1992; Fremaux et al., 1993).

In a screening programme of Lactobacillus strains set up to select for those producing bacteriocins that are inhibitory towards micro-organisms outside the genus Lactobacillus, we have isolated a strain of Lactobacillus acidopbilus (M46) producing a potent bacteriocin which inhibits growth of Listeria monocytogenes, Clostridium sporogenes and Brochothrix thermosphacta, but which affects only a few Lactobacillus strains (Vossen et al., 1994). The bacteriocin, acidocin B, is a protein and has an estimated size of $2.4 \mathrm{kDa}$. Acidocin $B$ production, which is plasmid-encoded, has been transferred to a non-producing L. plantarum strain (Vossen et al., 1994).

In this paper we present the nucleotide sequence of three clustered genes, at least one of which is involved in the production of acidocin B. From a comparison of the amino acid composition of purified acidocin $\mathrm{B}$ with the deduced amino acid sequences, one of the genes was identified as the gene encoding acidocin B. Our results also suggest that one of the other two genes encodes the immunity protein.

\section{METHODS}

Materials. All enzymes for molecular cloning were purchased from Boehringer or BRL and were used according to the recommendations of the suppliers.

Bacterial strains, plasmids and media. L. plantarum strain 80 (Scheirlinck et al., 1989) and L. fermentum NCK127 (Barefoot \& Klaenhammer, 1983) were maintained as frozen glycerol stocks at $-20^{\circ} \mathrm{C}$. Lactobacilli were cultivated in MRS broth (Difco) at $37^{\circ} \mathrm{C}$. For plating, MRS was solidified with $1.5 \%(\mathrm{w} / \mathrm{v})$ agar (Daishin). Erythromycin was used at a final concentration of $10 \mu \mathrm{g} \mathrm{ml}^{-1}$. For cloning in Escherichia coli the strain JM109 was used as the host. Plasmid pCV461 is a $14 \mathrm{~kb}$ plasmid from $L$. acidophilus M46 containing the genes for acidocin B production (Vossen et al., 1994). Plasmids pGKV21, a shuttle vector that can be propagated in Gram-positive and Gram-negative bacteria (Vossen et al., 1985), and $\mathrm{pEI} 2$, a derivative of the E. coli vector pUC19 (Posno et al., 1991), were used for subcloning DNA fragments. Plasmid pLPE24M* (* denotes a spontaneous highcopy-number mutant) is a derivative of pLPE24M, which was obtained by introduction of a multicloning site polylinker into pLPE323 (Pouwels \& Leer, 1993).

Isolation of plasmid DNA, bacterial transformation and DNA techniques. Isolation of Lactobacillus plasmid DNA, transformation of Lactobacillus and E. coli JM109, and DNA manipulations were all carried out as described previously (Posno et al., 1991; Leer et al., 1992). Nucleotide sequences were determined by the chain-termination method using plasmid DNA as the template and sequence-specific primers (Sanger et al., 1977).

Assay of bactericidal activity of acidocin B. This was carried out as described previously (Brink et al., 1994). In short, bacteria were cultivated overnight in MRS broth containing $2 \%(\mathrm{w} / \mathrm{v})$ glucose and $3 \%(\mathrm{w} / \mathrm{v})$ calcium carbonate. After centrifugation, the supernatant solution was filter-sterilized and the $\mathrm{pH}$ was adjusted to $7 \cdot 0$. Bacteriocin activity was measured with $C$. sporogenes as the target organism by pipetting $20 \mu \mathrm{l}$ into wells punched in a nutrient agar plate. After $20 \mathrm{~h}$ incubation the formation of inhibition zones around the wells was examined.

Production and purification of acidocin B. L. acidophilus M46 was cultivated in MRS broth overnight at $37^{\circ} \mathrm{C}$. Cells were removed by centrifugation and the $\mathrm{pH}$ of the supernatant was adjusted to 7.7 with sodium hydroxide. Sodium chloride was added to saturation and the solution was extracted with 2propanol. The 2-propanol phase was collected and concentrated by evaporation. The concentrated residue was taken up in $10 \mathrm{ml}$ water followed by extraction with 1-butanol. The butanol extract was concentrated by evaporation and the residue was resuspended in $0 \cdot 1 \%$ trifluoroacetic acid (TFA). This sample was further purified by reversed-phase HPLC on a C3 column, using a gradient of $16 \%$ to $51 \%(\mathrm{v} / \mathrm{v}) 2$-propanol in acetonitrile acidified with TFA $(0 \cdot 1 \%)$. Buffer $A$ was made up as $0 \cdot 1 \%$ TFA in water. Buffer B was composed of $80 \%(\mathrm{v} / \mathrm{v})$ 2-propanol in acetonitrile acidified with TFA $(0 \cdot 1 \%)$. The gradient consisted of a $20 \mathrm{~min}$ linear gradient from $80 \% \mathrm{~A} / 20 \% \mathrm{~B}$ to $35 \% \mathrm{~A} / 65 \% \mathrm{~B}$. The $A_{210}$ of the effluent was monitored. Fractions were evaporated, resuspended in water and assayed for bactericidal activity. Fractions showing activity were combined and subjected to a second HPLC purification cycle. After evaporation, the resuspended fractions were again assayed for activity.

Amino acid analysis. Purified acidocin $\mathrm{B}$ was hydrolysed under $\mathrm{HCl}$ vapour at $116^{\circ} \mathrm{C}$ for $24 \mathrm{~h}$ and derivatized with phenyl isothiocyanate. Quantification of the phenylthiocarbamyl amino acids obtained was carried out using reversed-phase HPLC (Noort et al., 1991).

\section{RESULTS AND DISCUSSION}

\section{Cloning of acidocin-B-encoding genes}

We have previously shown that the $14 \mathrm{~kb}$ plasmid pCV461 from $L$. acidopbilus M46 harbours the genetic information for production of acidocin B. This information could be transferred to a non-producing $L$. plantarum strain (Vossen et al., 1994). To determine which parts of the plasmid are involved in bacteriocin production, pCV461 was digested with restriction enzymes, and the fragments obtained were subcloned in pGKV21 and used to transform L. plantarum 80 . The culture medium from transformants cultivated in MRS broth containing erythromycin was assayed for the presence of acidocin B using $C$. sporogenes as indicator strain in a plate assay. The results (Fig. 1) show that the smallest fragment that confers the capacity to produce acidocin $\mathrm{B}$ is contained within a $4 \mathrm{~kb}$ XbaI-Bam HI fragment (pCV461-3). When the unique PstI site present within the XbaI-BamHI fragment was destroyed by removal of the protruding ends with Klenow enzyme and re-ligation, the resulting plasmid (pCV461-6) was no longer able to produce active acidocin B. Apparently, the Pst $\mathrm{I}$ site is located in a region which is essential for acidocin B production.

\section{DNA sequence analysis}

The nucleotide sequence of a $2 \cdot 2 \mathrm{~kb}$ region surrounding the PstI site was determined (Fig. 2). Three consecutive ORFs could be identified which potentially encoded 


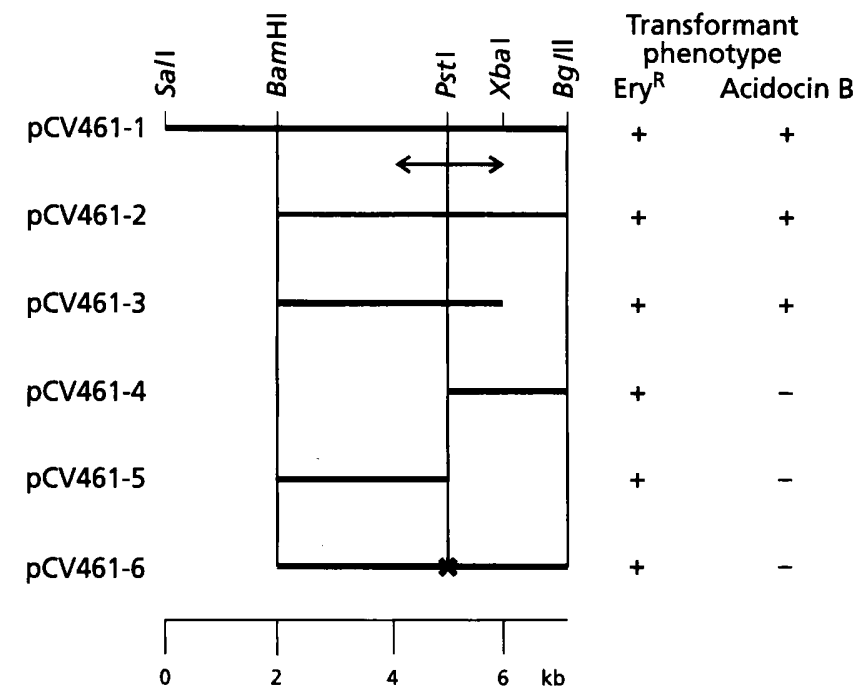

Fig. 1. Restriction-endonuclease-derived fragments from plasmid pCV461 cloned into pGKV21. The $7 \mathrm{~kb}$ Sall-Bg/ll fragment corresponds with the left circle segment of pCV461 as published by Vossen et al. (1994). Supernatants of $L$. plantarum transformants (erythromycin-resistant) containing the different cloned fragments were assayed for acidocin B activity. The eliminated Pstl site is indicated by $X$. The DNA sequence of the region surrounding the Pstl site $(\leftrightarrow)$ was determined.

polypeptides composed of 60,91 and 114 amino acids, respectively. A fourth ORF (not shown) was found with a polarity opposite to that of the others. It overlaps the second ORF and could encode a polypeptide of 59 amino acids. The predicted Pst I site is located in ORF-2, implying that this ORF is essential for production of acidocin B.

Each of the ORFs is preceded by a typical translation initiation region comprising a Shine-Dalgarno element at a distance of 6-10 nucleotides before the translation start codon. The intergenic regions between ORFs 1-3 are 108 and 85 nucleotides long. In the intergenic region between ORF-2 and ORF-3 a palindromic sequence (nt 741-768; see Fig. 2) was found, which can form a stable stem-loop structure $\left[\Delta G=-16.1 \mathrm{kcal} \mathrm{mol}^{-1} \quad\left(-67.4 \mathrm{~kJ} \mathrm{~mol}^{-1}\right)\right]$ followed by a series of $\mathrm{T}$ residues, resembling thoindependent transcription terminator sequences (Platt, 1986). If this sequence indeed functions as a transcription terminator, it would imply the presence of a promoter located between the putative terminator and the start of ORF-3 (nt 788). Alternatively, the promoter might overlap with the terminator, allowing a fraction of RNA polymerase molecules, which pause at this site, to read through the terminator sequence. A sequence (TAGACT $-21 \mathrm{nt}$ - TATTAAT) showing resemblance to $\sigma^{70}$ promoter elements is present $30 \mathrm{nt}$ upstream of the translation start of ORF-3, partially overlapping the hypothetical terminator sequence. Upstream of ORF-1 and downstream from ORF-3, sequences were found (not shown), 800 and $350 \mathrm{nt}$ in length, which do not seem to code for a polypeptide. These sequences show no particular
AAGCTTGAGAAGAAAGATACCGATAAGGCCTTATTGATTTACACGATGGTCATTTTTGTT

GTCAATTCTATCCTCCCGATATTTTCACTTTTAGGAAGGTAGCATGTAGGTAAATAATCT

$\frac{\text { rbs }}{\text { TTAAGGAGACAATCAGGCATGGATAAGAAACAAAATATTATTTGAAGTATTATACAT }}$ $\begin{array}{llllllllllllll}M & D & K & K & T & K & I & L & F & E & V & L & Y & I\end{array}$

CATCTGTATAATAGGCCCTCAATTTATATTATTTGTGACTGCAAAAAACAATATGTATCA $\begin{array}{llllllllllllllllllll}I & C & I & I & G & P & Q & F & I & L & F & V & T & A & K & N & N & M & Y & Q\end{array}$

GTTGGTGGGTTCGTTTGTTGGAATAGTATGGTTTTCGTATATTTTTTGGTATATTTTTTi $\begin{array}{llllllllllllllllllll}L & V & G & S & F & V & G & I & V & W & F & S & Y & I & F & W & Y & I & F & F\end{array}$

CAAACAACATAAAAAATGTAGTATACCACTTGTTTATTGATTATTAAGGGCTTATAAT

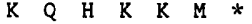

AATGGTGTAATATTTACTACAAAAAGGTACGTACACTCGTAATGGATTTCCTATGGGAGG

AAGATACTATGGTTACTAAGTACGGACGTAATTTAGGTTTGAGCAAGGTAGAGTTGTTTG $\begin{array}{llllllllllllllllll}M & V & T & K & Y & G & R & N & \text { L } & G & \text { L } & \text { S } & \text { K } & \text { V } & \text { E } & \text { L } & \text { F } & \text { A }\end{array}$

CAATTTGGGCGGTTTTAGTAGTTGCTCTTTTATTGGCCACAGCGAACATTTATTGGATTG

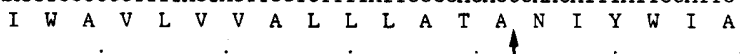

CTGATCAATTCGGATTCATTTAGCGACTGGAACAGCCCGTAAGTTATTAGATGCAGTGG

$\begin{array}{llllllllllllllllllll}D & Q & F & G & \text { I } & \text { H } & \text { L } & \text { A } & \text { T } & \text { G } & \text { T } & \text { A } & \text { R } & K & \text { L } & \text { L } & \text { D } & \text { A } & \text { V } & \text { A }\end{array}$

CTTCTGGTGCCTCATTGGGAACTGCCTTTGCTGCTATTTTGGGCGTGACATTACCTGCAT

$\begin{array}{llllllllllllllllllll}S & G & A & S & L & G & T & A & F & A & A & I & L & G & V & T & L & P & A & W\end{array}$ PSTI

GGGCTTTGGCAGCTGCAGGAGCATTGGGAGCGACTGCGGCTTAGTGATTATAAAGCTTTA

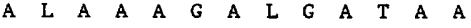

TGAATAGACTATTCAAAAAGGCTAATAGGTATTAATACCTATTAGCCTTTTCTTAGGA

GACAGATTTGATTAGAATTAATAACGTAAAGATACTAATTCCATTAGTCCTGTTTATTGG $\begin{array}{lllllllllllllllllll}L & I & R & I & N & N & V & \text { K } & \text { I } & \text { L } & \text { I } & \text { P } & \text { L } & \text { V } & \text { L } & \text { F } & \text { I } & G\end{array}$

AATACTCGTTGGTGCCGGATATGAATACTATAGTTCAGGAAATTTCAAGTTGAGATGAT

$\begin{array}{llllllllllllllllllll}I & L & V & G & A & G & Y & E & Y & Y & S & S & G & N & F & Q & V & E & M & M\end{array}$

GAAGGAAGTCAATATAAATCAATTAATGGCTCTATCTAGCATTATCTTAAAAAATACTGC

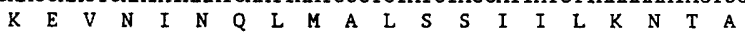

CGCGTTCCTATTACTGGGTTIAACATTGATTGTTGGAAAATGGTTCATAATACTATTCTT 1020 $\begin{array}{clllllllllllllllllllll}\text { A } & \text { F } & \text { L } & \text { L } & \text { L } & \text { G } & \text { L } & \text { T } & \text { L } & \text { I } & \text { V } & \text { G } & \text { K } & \text { W } & \text { F } & \text { I } & \text { I } & \text { L } & \text { F } & \text { F }\end{array}$

TTTAATAAATGGATTTAACATAGGAATGTTCAGTGTTCATTTATCAATAATTGAGTTTAT 1080 $\begin{array}{lllllllllllllllllllll}L & I & N & G & F & N & I & G & M & F & S & V & H & L & S & I & I & E & F & I\end{array}$ AGTATTGTTTTTACCACATGGaATTTTTGAGTATGTAGTATTCTATTATTGaGaGTAaÁ 1140

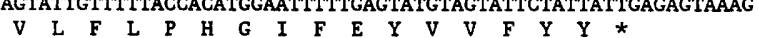

TTTTCATAATAGATTTAGATGGATCGCCTAGTAAAGCTT

Fig. 2. DNA sequence surrounding the Pstl site. Putative ribosome-binding sites (rbs) are indicated. A potential transcription terminator sequence is shown by horizontal arrows. The putative processing site in ORF- 2 is indicated by a vertical arrow. The nucleotide sequence of both strands has been determined.

features, such as promoter sequences, terminator elements or palindromic structures capable of binding DNAbinding proteins (Sauer \& Pablo, 1984).

\section{Identification of ORF-2 as the acidocin-B-encoding gene}

Acidocin B was purified in an attempt to determine part of its amino acid sequence. The compound could be purified to apparent homogeneity by taking advantage of its hydrophobic nature. More than $95 \%$ of the bactericidal activity could be recovered in the organic phase after extraction of the supernatant with 2-propanol. Subsequent purification of the protein by repeated reversedphase HPLC resulted in a highly purified preparation 


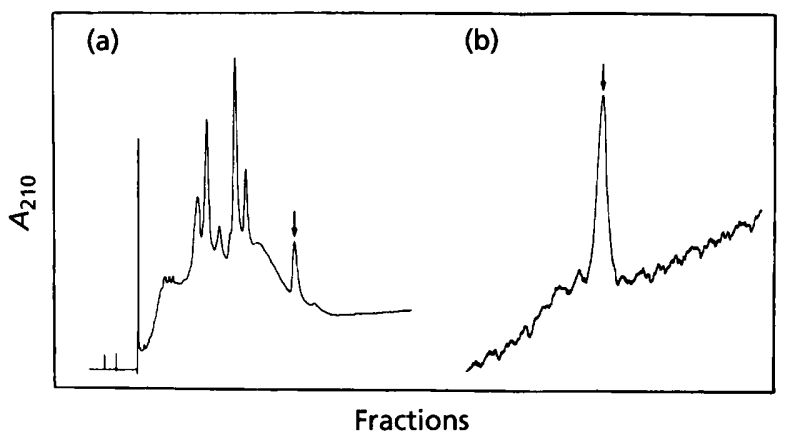

Fig. 3. Purification of acidocin B by HPLC. Arrows indicate peak fractions containing bactericidal activity in a $C$. sporogenes plate assay. Elution profiles (a) and (b) represent first and second purification cycles, respectively.

Table 1. Amino acid composition of acidocin B

\begin{tabular}{|c|c|c|}
\hline $\begin{array}{l}\text { Amino } \\
\text { acid }\end{array}$ & Sample & $\begin{array}{c}\text { No. of } \\
\text { residues } \\
\text { (deduced } \\
\text { from DNA } \\
\text { sequence) }\end{array}$ \\
\hline Asx & 2 & 2 \\
\hline Glx & $1-2$ & 1 \\
\hline Ser & 3 & 3 \\
\hline Gly & 8 & 7 \\
\hline His & 1 & 1 \\
\hline Arg & 1 & 1 \\
\hline Thr & 5 & 5 \\
\hline Ala & $15-16$ & 18 \\
\hline Pro & $1-2$ & 1 \\
\hline Tyr & $0-1$ & 1 \\
\hline Val & $2-3$ & 2 \\
\hline Met & - & - \\
\hline Cys & * & - \\
\hline Ile & 4 & 4 \\
\hline Leu & 8 & 8 \\
\hline Phe & 2 & 2 \\
\hline Lys & 1 & 1 \\
\hline $\operatorname{Trp}$ & - & 2 \\
\hline
\end{tabular}

* Oxidation products detected.

(Fig. 3b) which displayed bactericidal activity against $C$. sporogenes. The activity of the purified polypeptide against other test bacteria has not yet been determined.

The presence of a single protein fraction with acidocin $B$ activity suggests that acidocin $B$ is a single peptide. This conclusion must, however, be regarded with some reservation, as the purified peptide had lost most of its activity. Individual peptides of two-component bacteriocins such as lactacin $\mathrm{F}$ exhibit a low intrinsic activity. The activity and specificity can be altered by complementation with the missing peptide (Allison et al., 1994). We therefore cannot rule out the possibility that acidocin B is composed of two peptides, and that the purification procedure resulted in separation of the two constituents.

Attempts to determine the N-terminal amino acid sequence of the purified peptide have been unsuccessful, suggesting that the $\mathrm{N}$-terminal amino acid is blocked. The amino acid composition of the purified peptide indicates that it may contain as many as 59-62 residues (Table 1 ). Comparison of the amino acid composition of the purified peptide with the deduced amino acid sequences of the four ORFs indicates that acidocin B is encoded by ORF2. An almost perfect correlation between the amino acid composition and the deduced amino acid sequence was found, assuming that acidocin B is synthesized as a precursor of 91 amino acids which is processed between amino acids 32 and 33 (Fig. 4) to yield mature acidocin B ( 59 amino acids). The gene coding for acidocin $\mathrm{B}$ has been designated $a c d B$.

\section{Acidocin B shows features typical for class I type peptide bacteriocins but lacks a Gly-Gly processing site}

Acidocin B shows features that are characteristic of class I type peptide bacteriocins. The peptide is heat-stable and has a size similar to that of other members of this class. Acidocin B has a high Ala content $(30 \%)$, and together with Leu, Ile, Val, Phe, Trp and Gly, the percentage of non-polar residues is 70 (Table 1). The extreme hydrophobic nature of acidocin B explains its aberrant migration behaviour in SDS-polyacrylamide gels (Vossen et al., 1994) and its behaviour during purification. Acidocin B and the putative polypeptides encoded by ORFs 1 and 3 contain transmembrane helices (although they do not show any amphipathic properties) as observed in lactococcin G (Nissen-Meyer et al., 1992). Acidocin B lacks cysteine residues, which rules out the possibility that the peptide is a lantibiotic (Kellner \& Jung, 1989). No sequence homology was observed between acidocin $\mathrm{B}$ and bacteriocins from other LAB.

Inspection of the amino acid sequence of the putative leader peptide of acidocin B shows the presence of two cationic amino acids near the $\mathrm{N}$-terminus, a high percentage of hydrophobic amino acids (13 Leu, Val and Ile) in the central region, and two small, neutral amino acids at positions -3 and -1 relative to the cleavage site (Fig. 2 ). The putative secretory signal peptide could form an $\alpha$ helical structure ending immediately after the cleavage site. Such a sequence conforms to the rules of von Heijne (1983).

No Gly-Gly doublet, a characteristic feature of processing sites in class I bacteriocins (Kok et al., 1993), is found immediately upstream of the predicted cleavage site, or in its vicinity. Apparently, secretion and processing of acidocin B does not take place by a signal-peptideindependent pathway with a dedicated peptidase recognizing the Gly-Gly motif. In addition acidocin B does not appear to be exported by a signal-sequence-independent pathway requiring the products of $\operatorname{lcn} C$ and $\operatorname{lcn} D$ as was observed for lactococcin A (Belkum et al., 1992). In the $\operatorname{lc} A$ operon $\operatorname{lc} n C$ and $\operatorname{lcn} D$ are located immediately 

460
470
480
490
500

(a) GGT . TTG . AGC . AAG . GTA . GAG . TTG . TTT . GCA . ATT . TGG . GCG . GTT . TTA . GTA . GTT . GCT . CTT . TTA . TTG . GCC . ACA . GCG . AAC

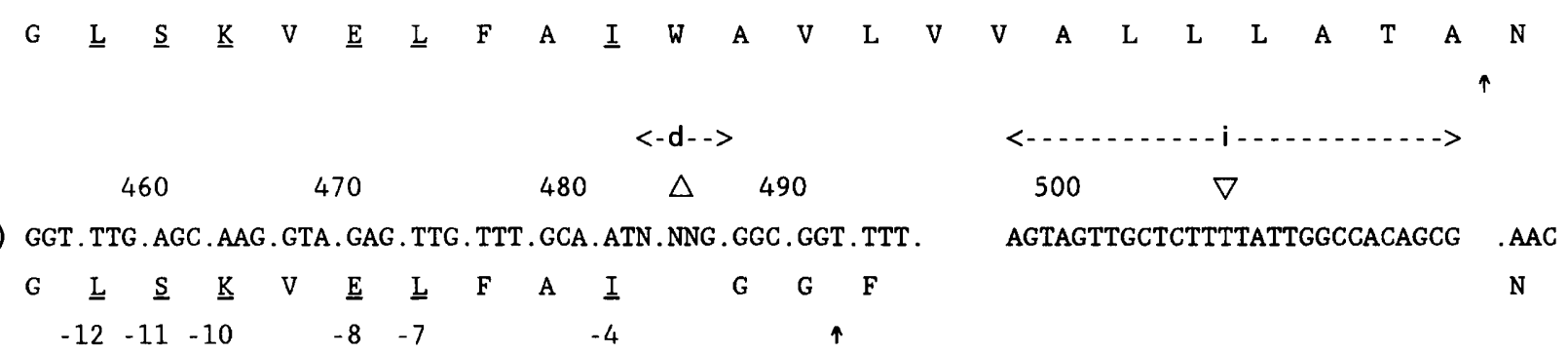

Fig. 4. Amino acid sequence of part of the $\mathrm{N}$-terminal region derived from ORF-2 (a) and a hypothetical ancestor sequence from which it could have been derived (b). Putative processing sites are indicated by vertical arrows. Conserved amino acids in $\mathrm{N}$-terminal sequences of class I bacteriocins are underlined. The DNA regions where a hypothetical deletion (d) and insertion (i) have occurred are given between horizontal arrows. Nucleotide 485 is given as $\mathrm{N}$ since deletion of any nucleotide at this position will result in an lle codon.

upstream of the bacteriocin-encoding gene, $\ln A$. The size of the remaining unidentified sequences of the $X b a \mathrm{I}-$ Bam HI fragment of pCV461-3 is insufficient to carry genes of this size. Although the possibility that LcnC- and LcnD-like proteins are chromosomally encoded cannot be excluded it seems unlikely that acidocin $\mathrm{B}$ is exported by this route, as processing through this pathway also relies on the presence of a Gly-Gly doublet. From these data we tentatively conclude that the acidocin $\mathrm{B}$ precursor is processed by the general signal-sequencedependent peptidase.

The apparent paradox that acidocin B belongs to class I bacteriocins as judged from its (physico)chemical and biological properties, but is not exported and processed by a Gly-Gly-dependent protease, may be resolved by assuming that acidocin $\mathrm{B}$ has evolved from an ancestor protein by means of two frameshift mutations $(-1$ and +1 ) which have changed the reading frame in the region between the mutations. By deletion of a nucleotide between coordinates 429 and 487 in the ancestor protein, the ancestral sequence TTG.GGC.GGT.TTT (LeuGly-Gly-Phe) would read in AcdB as TGG.GCG. GTT.TTA (Trp-Ala-Val-Leu). By insertion of a nucleotide in the ancestor protein between coordinates 497 and 523 , which generates the consensus sequence for a signalpeptide-dependent protease, the original reading frame would be restored. As a result of the two mutations the mature bacteriocin would have been truncated by 10 amino acids. It should be noted that hydrophobic amino acids are found at positions $-4(\mathrm{I}),-7(\mathrm{~L})$ and $12(\mathrm{~L})$, and charged amino acids at $-8(\mathrm{E})$ and $-10(\mathrm{~K})$, and a Ser residue at -11 with respect to the presumed Gly-Gly cleavage site (Fig. 4). In other class I LAB bacteriocins these positions are occupied by the same amino acids (Fremaux et al., 1993). If we assume that these residues were conserved to ensure the functionality of this part of the protein, this would mean that the region in which the nucleotide was deleted can be narrowed down to the sequence between nucleotides 485 and 488 . The similarity of the N-terminal amino acid sequence of the acidocin $\mathrm{B}$ precursor with that of class I bacteriocins, but the presence of the signal peptide cleavage site would suggest that terminal sequences of Gly-Gly-dependent proteases and signal sequences may be interchanged.

\section{Features of other ORFs}

ORFs 1 and 3 code for highly hydrophobic polypeptides (58 and $64 \%$ hydrophobicity), as was observed for bacteriocins and immunity proteins of other organisms (Belkum et al., 1992; Nissen-Meyer et al., 1992; Klaenhammer, 1993; Kok et al., 1993), whereas ORF-4 codes for a peptide of $40 \%$ hydrophobicity. A comparison of the deduced amino acid sequence or nucleotide sequence of ORFs 1, 3 and 4 with that of bacteriocins and immunity proteins from other organisms showed no obvious similarity. ORF-1 codes for a protein with a highly charged C-terminus (KQHKKM). Similar cationic sites are present at the C-terminal end of other peptide bacteriocins like lactococcins $A$ and $G$ (Holo et al., 1991), lactacin F (Muriana \& Klaenhammer, 1991) and pediocin PA-1 (Marugg et al., 1992). No Gly-Gly doublets were found in ORFs 1, 3 and 4.

The location of the acidocin-B-encoding gene between two genes which could code for small, hydrophobic peptides strongly resembles the organization of bacteriocin operons found in other organisms. The two genes coding for the two peptides constituting lactacin $F$ form an operon, together with a downstream ORF which could code for a hydrophobic polypeptide of 124 amino acids believed to be the precursor of the immunity protein (Fremaux et al., 1993). Similarly, in the lactococcin A, B and $M$ operons, and in the pediococcin PA-1 and leucocin A-UAL 187 operons, the gene coding for the bacteriocin is flanked at the $3^{\prime}$ end by a gene varying in size between 300 and 460 nucleotides, and coding for a small immunity protein (Klaenhammer, 1993; Kok et al., 1993). From the position of the gene relative to $a c d B$, and the similarity in length and hydrophobicity with other immunity-proteinencoding genes, it is tempting to speculate that ORF-3 codes for the immunity protein. 


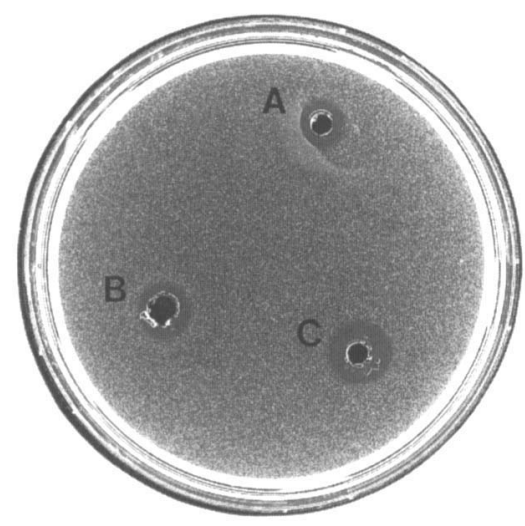

Fig. 5. Inhibition of $C$. sporogenes by culture supernatants (neutralized) of Lactobacillus in an agar well diffusion assay. Wells: A, culture supernatant of $L$. acidophilus M46; B and C, supernatant of $L$. plantarum transformants containing the $4 \mathrm{~kb}$ Xbal-BamHI fragment (Fig. 1) cloned in pGKV21 and pLPE24*, respectively.

\section{Expression of acidocin B in heterologous hosts}

The $4 \mathrm{~kb} \mathrm{XbaI-BamHI}$ fragment of pCV461 was cloned in the high-copy-number Lactobacillus vector pLPE24M* ( $\sim 80$ copies per bacterium) and in the low-copy-number vector pGKV21 ( 20 copies per bacterium). Both vectors were introduced into L. plantarum 80 . Acidocin B production by $L$. plantarum transformants was visualized using a plate assay. Fig. 5 shows that the level of acidocin B production of $L$. plantarum transformants increases as the copy number of the cloned acidocin-B-encoding genes increases. It appears that expression and secretion of acidocin B in L. plantarum is solely dependent on gene dosage and is not limited by host factors.

After introduction of pCV461-3 into L. fermentum NCK127, transformants were obtained that expressed acidocin $B$ (not shown). Since this organism is sensitive to acidocin $\mathrm{B}$, these results strongly suggest that the immunity-protein-encoding gene is present within the $4 \mathrm{~kb}$ DNA fragment, consistent with the above proposal that the immunity protein is encoded by ORF-3.

If we are correct in our assumption that acidocin $\mathrm{B}$ is processed by a signal-sequence-dependent peptidase, an enzyme which is ubiquitously present in bacteria, then acidocin $\mathrm{B}$ can, in principle, be synthesized in any bacterial species, unlike other non-lantibiotic and lantibiotic bacteriocins (Simonen \& Palva, 1993; Smith et al., 1987, 1988). Considering that at least some strains of Lactobacillus are sensitive to acidocin B, as demonstrated for L. fermentum NCK127, the acidocin-B-encoding genes may be useful for the development of food-grade vectors (Vossen et al., 1994).

\section{ACKNOWLEDGEMENTS}

We thank Drs Bart ten Brink, Ingolf Nes and Jos Huis in 't Veld for fruitful discussions and making data available prior to publication. We gratefully acknowledge the invaluable comments on the manuscript of an anonymous referee. This work was supported by grant BIOT-CT.91-0263 (SSMA) from the Biotechnology Research for Innovation, Development and Growth in Europe of the Commission of the European Communities.

\section{REFERENCES}

Allison, G. E., Fremaux, C. \& Klaenhammer, T. R. (1994). Expansion of bacteriocin activity and host range upon complementation of two peptides encoded within the lactacin $\mathrm{F}$ operon. $J$ Bacteriol 176, 2235-2241.

Barefoot, S. \& Klaenhammer, T. R. (1983). Detection and activity of lactacin B, a bacteriocin produced by Lactobacillus acidopbilus. Appl Environ Microbiol 45, 1808-1815.

Belkum, M. J. van, Kok, J. \& Venema, G. (1992). Cloning, sequencing, and expression in Escherichia coli of icnB, a third bacteriocin determinant from the lactococcal bacteriocin plasmid p9B4-6. Appl Environ Microbiol 58, 572-577.

ten Brink, B., Minekus, H., Leer, R. J., Vossen, J. M. B. M. \& Huis in 't Veld, J. (1994). Antimicrobial activity of lactobacilli: partial characterization and optimization of production of acidocin $\mathrm{B}$, a novel bacteriocin produced by Lactobacillus acidopbilus M46. J Appl Bacteriol 77, 140-148.

Fremaux, C., Ahn, C. \& Klaenhammer, T. R. (1993). Molecular analysis of the lactacin F operon. Appl Environ Microbiol 59, 3906-3915.

von Heijne, G. (1983). Patterns of amino acids near signal sequence cleavage sites. Eur J Biochem 133, 17-21.

Holo, H., Nissen, O. \& Nes, I. F. (1991). Lactococcin A, a new bacteriocin from Lactococcus lactis subsp. cremoris: isolation and characterization of the protein and its gene. $J$ Bacteriol 173, 3879-3887.

Gilliland, S. E. (1985). Bacterial starter cultures for foods. Boca Raton, Florida: CRC Press.

Kellner, R. \& Jung, G. (1989). Sequencing of peptide antibiotics containing unusual amino acids. Biosyst Eur News 7, 2-3.

Klaenhammer, T. R. (1993). Genetics of bacteriocins produced by lactic acid bacteria. FEMS Microbiol Rev 12, 39-86.

Kok, J., Holo, H., van Belkum, M. J., Haandrikman, A. J. \& Nes, I. F. (1993). Nonnisin bacteriocins in lactococci: biochemistry, genetics, and mode of action. In Bacteriocins of Lactic Acid Bacteria, pp. 121-150. Edited by D. Hoover \& L. Steenson. New York: Academic Press.

Leer, R. J., van Luijk, N., Posno, M. \& Pouwels, P. H. (1992). Structural and functional analysis of two cryptic plasmids from Lactobacillus pentosus MD353 and Lactobacillus plantarum ATCC 8014. Mol \& Gen Genet 234, 265-274.

Marugg, J. D., Gonzalez, C. F., Kunka, B. S., Ledeboer, A. M., Pucci, M. J., Toonen, M. Y., Walker, S. A., Zoetmulder, L. C. M. \& Vandenbergh, P. A. (1992). Cloning, expression, and nucleotide sequence of genes involved in production of pediocin PA-1, a bacteriocin from Pediococcus acidilactici PAC1. Appl Environ Microbiol 58, 2360-2367.

Muriana, P. M. \& Klaenhammer, T. R. (1991). Cloning, phenotypic expression, and DNA sequence of the gene for lactacin $F$, an antimicrobial peptide produced by Lactobacillus spp. J Bacteriol 173, 1779-1788.

Nissen-Meyer, J., Holo, H., Havarstein, L. S. \& Nes, I. F. (1992). A 
novel lactococcal bacteriocin whose activity depends on the complementary action of two peptides. J Bacteriol 174, 5686-5692. van Noort, J. M., Baan, J., van der Drift, A. C. M., Boots, A. M. H., Wagenaar, J. P. A. \& Boog, C. J. P. (1991). Processing by endosomal proteases determines which parts of sperm whale myoglobin are eventually recognized by T-cells. Eur J Immunol 21, 1989-1996.

Platt, T. (1986). Transcription termination and regulation of gene expression. Ann Rev Biochem 55, 339-372.

Posno, M., Leer, R. J., van Luijk, N., van Giezen, M. J. F., Heuvelmans, P. T. H. M. \& Pouwels, P. H. (1991). Incompatibility of Lactobacillus vectors with replicons derived from small cryptic Lactobacillus plasmids and segregational instability of the introduced vectors. Appl Environ Microbiol 57, 1822-1828.

Pouwels, P. H. \& Leer, R. J. (1993). Genetics of lactobacilli: plasmids and gene expression. Antonie Leewwenboek 64, 85-107.

Sanger, F., Nicklen, S. \& Coulsen, A. R. (1977). DNA sequencing with chain-terminating inhibitors. Proc Natl Acad Sci USA 74, 5463-5467.

Sauer, R. T. \& Pabo, C. O. (1984). Protein-DNA recognition. Ann Rev Biochem 53, 293-321.

Scheirlinck, T., Mahillon, J., Joos, H., Dhaese, P. \& Michiels, F. (1989). Integration and expression of $\alpha$-amylase and endoglucanase genes in the Lactobacillus plantarum chromosome. Appl Environ Microbiol 55, 2130-2137.
Simonen, M. \& Palva, I. (1993). Protein secretion in Bacillus species. Microbiol Rev 57, 101-137.

Smith, H., Bron, S., van Ee, J. \& Venema, G. (1987). Construction and use of signal sequence selection vectors in E. coli and B. subtilis. J Bacteriol 169, 3321-3328.

Smith, H., de Jong, A., Bro, S. \& Venema, G. (1988). Characterization of signal-sequence-coding regions selected from the Bacillus subtilis chromosome. Gene 70, 351-361.

Tagg, J. R., Dajani, A. S. \& Wannamaker, L. W. (1976). Bacteriocins of Gram-positive bacteria. Microbiol Rev 40, 722-756.

van der Vossen, J. M. B. M., Kok, J. \& Venema, G. (1985). Construction of cloning, promoter-screening, and terminatorscreening shuttle vectors for Bacillus subtilis and Streptococcus lactis. Appl Environ Microbiol 50, 540-542.

van der Vossen, J. M. B. M., van Herwijnen, M. H. M., Leer, R. J., ten Brink, B., Pouwels, P. H. \& Huis in 't Veld, J. H. J. (1994). Production of acidocin B, a bacteriocin of Lactobacillus acidophilus M46 is a plasmid encoded trait : plasmid curing, genetic marking by in vivo plasmid integration, and gene transfer. FEMS Microbiol Lett $116,333-340$

Received 22 June 1994; revised 23 September 1994; accepted 11 October 1994 (publication of this paper was delayed after acceptance by a patent application). 